\title{
HEALTH CARE PROVIDERS`KNOWLEDGE AND SKILLS RELATED TO INHALER MEDICATIONS TECHNIQUES AT MANSOURA CHEST DISEASE HOSPITAL ${ }^{1}$ wafaa Mahmoud Elboraey, ${ }^{2}$ Hanan Mohamed Mohamed, ${ }^{3}$ Wafaa Gamil Mohamed \\ ${ }^{1,2,3}$ Medical-Surgical Nursing Department, Faculty of Nursing-Mansoura University E-mail of corresponding author: wafaaboraey171@gmail.com.
}

\begin{abstract}
Background:Inhaled therapy is the cornerstone of asthma management in that it optimizes the delivery of the medication to the site of action. The effectiveness of inhaled therapy is affected by the correct choice of the device and proper inhalation technique. Misuse of an inhaler medication is common in clinical practice, and proper training of patients and health care providers is important. The aim was to assess health care provider`s knowledge and skills related to inhaler medications techniques at Mansoura Chest Disease Hospital. Method the study use a descriptive exploratory research design. Setting: The study was conducted at Mansoura Chest Disease Hospital .The study sample: was all available health care providers( 102 nurse and 40 physician) affiliated to the previously mentioned setting. Tools: Structured Interview Questionnaire 1) Socio-Demographic characteristic 2) health care provider`s knowledge related to inhaler medications 3) Inhaler medications checklist. Consists of three parts: 3.1:Metered dose inhaler (MDI) checklist. 3.2:Accuhaler Inhaler Technique (Diskus) checklist.3.3:aerolizer /Handhaler Technique checklist. Results, showed that the majority $(90.2 \%)$ of the nurses reported that they didn't receive any training courses regarding inhaler whereas, more than two fifths $(42.5 \%)$ of physician received. There was a significant relation between the participant age, years of experience, and training courses. There was a highly statistical significant relation between nurses and physician and their total level of knowledge and skills. Recommendation, study recommended that development of educational program for doctors and nurses to improve their knowledge and skills regarding inhalers to prevent misuse of inhalers.

Key words: Accuhaler (Diskus), Handhaler , inhalation technique, inhaled therapy, knowledge, skills, pMDI
\end{abstract}

\section{Introduction:}

The number of pulmonary diseases that are effectively treated by aerosolized medicine continues to grow. These diseases include asthma and chronic obstructive lung disease Obstructive airway diseases including asthma are leading causes of mortality and morbidity worldwide with profound economic and social burden $^{(\mathbf{1 , 2})}$.Effective medications for asthma and COPD are available and all patients who are symptomatic merits a trial of drug treatment. The medications for asthma and COPD currently available can reduce or abolish symptoms, increase exercise capacity, reduce the number and severity of exacerbations, and improve health status. The therapeutic classes of medications for asthma and COPD are bronchodilators, anti inflammatory agents , and augmentation therapy . There are three types of bronchodilator are in common clinical use : $\beta$ - agonists, anticholinergic drugs and methylxanthines ${ }^{(3)}$. A medical aerosol is any mixture of drug particles and gas . Aerosol treatments can be delivered with a portable, hand-held device that can be carried in patient purse or pocket, such as 
a pressurized metered-dose inhaler (pMDI) or a dry-powder inhaler (DPI) ${ }^{(\mathbf{4})}$.A number of misconceptions and myths about the inhalation therapy like use of inhaler is dangerous ; it damages lungs and heart, it is the last resort, inhalers were very costly compared to oral medications, and habit forming; and it is difficult to use etc. These may affect the treatment seeking behavior and compliance .Another important cause of poor compliance may be inappropriate techniques of using inhalation devices. This may result in misuse or overdose of drugs and may lead to diminished response to therapy. The child may require repeated hospitalizations ${ }^{(\mathbf{5})}$.Incorrect use of inhalers, including under- and over-dosing driven by patient error, can also impact safety and tolerability . Inappropriate patient use has also been cited as a primary contributing factor in adverse events. Misuse of an inhaler is common in clinical practice, and proper training of patients and nurses is important to ensure the correct use of the device. Patient technique has a large impact on the amount of active drug delivered to the site of action and, therefore, on the efficacy and disease control. ${ }^{(6)}$.A little attention is given to the training of health care providers, and to the patient-to- health care providers education interaction. Current guidelines recommend that health care providers follow adherence management strategies however; evidence for these interventions is weak ${ }^{(7)}$.

1. The study aim: the aim of the study was to assess health care providers knowledge and skills related to inhaler medications techniques at Mansoura Chest Disease Hospital.

2. Subjects \& method :

- Research Design:A descriptive exploratory research design was used in this study.
- Setting:This Study was conducted at Mansoura Chest Disease Hospital in delta region.

Participants:It consisted of all available health care providers ( 102 nurse and 40 physician) affiliated to the previously mentioned setting.

3.4 Tools: $\quad$ Structured Interview Questionnaire which consists from three parts

3.4.1- part I:Socio-Demographic data sheet , It include demographic data of health care provider as name, age, level of education , years of experience, place of work, and previous training courses, etc.

3.4.2- part II: Health Care Provider's knowledge related to inhaler medications, It was used to assess health care provider's knowledge about inhalers

.This questionnaire of inhaler knowledge had 25 items in total and included 6 categories. Questions were in the form of multiple choice questions (MC) one point for each correct answer ero point for an incorrect answer or I don t know answer. The total score were classified as the following:Poor knowledge : less than 50\% Average knowledge : 50-65

$\%$ Good knowledge : more than $65 \%$ (8,9).

3.4.3-part III : Inhaler medications performance checklist, used to assess health care providers' performance related to inhaler usage by asking participants to demonstrate the inhaler technique with a placebo device by using prepared checklists derived from (GINA , 2015) ; (Australian Respiratory Guidelines(ARG), 2008) which consists of three checklist:

3.4.3.1: Metered dose inhaler (MDI) checklist used to assess technique of using (MDI) and included 10 items .

\subsubsection{Accuhaler Inhaler}

Technique (Diskus) checklist :Used to assess technique of using Accuhaler (Diskus)and include 9 items. 
HEALTH CARE PROVIDERS`KNOWLEDGE AND SKILLS etc...

: Aerolizer/ Hand haler Technique checklist :Used to assess technique of using aerolizer / Handhaler and included 13 items . Scoring system: The steps in the form of Yes and No. A correct step was scored 1; an incorrect one was scored 0. Scores of each item were summed up .The total score were collected and evaluated as the following Poor skills : less than 50\% Average skills :50-65\%, Good skills : more than $65 \%{ }^{(8,9)}$.

\section{4- Methods:}

- An official approval for conducting the study was obtained from the research ethics committee of faculty of Nursing of Mansoura University

- An oral consent was obtained from each participant in this study after explaining the study aim. Participants were assured that the information is confidential and used for study purpose only.

- The participants had the right to withdraw from the study at any time without giving any reasons

- A pilot study was applied on $10 \%$

(15) participant of total number of health care provider's to test the simplicity, clarity of the questions and time frame needed for interview. The participants of the pilot study were excluded from the study group . Minor modifications were done accordingly.

5. Results:The data collected were analyzed statistically and the results are categorized as following parts:The collected data were analyzed statistically and the results were categorized into the following parts:

Part I: Socio-demographic characteristics of the studied subjects (Table 1).

Part II: Health care providers' knowledge related to inhaler medications (Table 2).

Part III: Inhaler medications performance checklist (Table 3-6).

The demographic characteristics of the participants was shown in Table (5.1) at baseline; Around three quarters $(72.5 \%)$ of nurses at the age group 20-30 years old, while around two fifths of the physician aged 20-30 years and 31 to 40 years old (40\% and $45 \%$ respectively). Regarding level of education, more than half of the physician has master degree, whereas, half of nurses reported that they have diplome and the rest of them have Bachelor degree in nursing with the same percentage $(57.5 \%, 50 \%$, and $50 \%$ respectively). More than three quarters of the participants nurses and physician reported that they have 1-10 years of experience (75\% and $83.3 \%$ respectively).

The majority (90.2\%) of the nurses reported that they didn't receive any training courses regarding inhaler whereas, more than two fifths $(42.5 \%)$ of physician received. Finally, there is a significant relation between the participant age, years of experience, and training courses ( $p$ $0.000,0.03$, and 0.000 respectively), while the table shows no statistically significant relation regarding level of education. 
wafaa Mahmoud Elboraey et., al.

Table (5.1):Frequency Distribution of the Study Participant Regarding General Characteristics $(n=142)$.

\begin{tabular}{|c|c|c|c|c|c|}
\hline \multirow[t]{2}{*}{ General characteristics } & \multicolumn{2}{|c|}{$\begin{array}{c}\text { Physician } \\
(n=40)\end{array}$} & \multicolumn{2}{|c|}{$\begin{array}{c}\text { Nul ses } \\
(n=102)\end{array}$} & \multirow[t]{2}{*}{ Significant } \\
\hline & $\mathrm{No}$ & $\%$ & No & $\%$ & \\
\hline $\begin{array}{l}\text { Age (year) } \\
20-30 \\
31-40 \\
41-50 \\
51-58\end{array}$ & $\begin{array}{l}16 \\
18 \\
2 \\
4\end{array}$ & $\begin{array}{l}40.0 \\
45.0 \\
5.0 \\
10.0\end{array}$ & $\begin{array}{c}74 \\
28 \\
0 \\
0\end{array}$ & $\begin{array}{l}72.5 \\
27.5 \\
0.0 \\
0.0\end{array}$ & $\begin{array}{l}X^{2}=22.834 \\
\mathrm{P}=0.000 * *\end{array}$ \\
\hline $\begin{array}{l}\text { Level of education } \\
\text { Diplom } \\
\text { Bachelor } \\
\text { Master } \\
\text { Doctorate } \\
\end{array}$ & $\begin{array}{c}0 \\
16 \\
23 \\
1\end{array}$ & $\begin{array}{c}0.0 \\
40.0 \\
57.5 \\
2.5 \\
\end{array}$ & $\begin{array}{c}51 \\
51 \\
0 \\
0\end{array}$ & $\begin{array}{c}50.0 \\
50.0 \\
0.0 \\
0.0 \\
\end{array}$ & $\begin{aligned} X 2 & =3.469 \\
P & =0.18\end{aligned}$ \\
\hline $\begin{array}{l}\text { Years of experience } \\
1-10 \text { years } \\
>10-20 \text { years } \\
\text { More than } 20 \text { years }\end{array}$ & $\begin{array}{l}30 \\
6 \\
4\end{array}$ & $\begin{array}{l}75.0 \\
15.0 \\
10.0\end{array}$ & $\begin{array}{c}85 \\
16 \\
1\end{array}$ & $\begin{array}{l}83.3 \\
15.7 \\
1.0\end{array}$ & $\begin{array}{c}X 2=6.894 \\
P=0.03^{*}\end{array}$ \\
\hline $\begin{array}{l}\text { Previous training course } \\
\text { No } \\
\text { Yes }\end{array}$ & $\begin{array}{l}23 \\
17 \\
\end{array}$ & $\begin{array}{l}57.5 \\
42.5 \\
\end{array}$ & $\begin{array}{l}92 \\
10 \\
\end{array}$ & $\begin{array}{c}90.2 \\
9.8 \\
\end{array}$ & $\begin{array}{l}X 2=19.947 \\
P=0.000^{* *}\end{array}$ \\
\hline
\end{tabular}

-* p-value $\leq 0.05$ (significant)

$-* *$ p-value $\leq 0.001$ (highly significant)

Table (5.2) : Reveals that, there was a highly statistical significant relation between nurses and physician and their total level of knowledge, medication technique effect, side effect and inhaler

complication and effect of medication on general health $\left(\chi^{2}=37.202 \& \mathrm{p}=0.000, \chi^{2}\right.$ $=43.312 \& \mathrm{p}=0.000, \chi^{2}=8.083 \& \mathrm{p}=0.02$ and $\left.\chi^{2}=26.389 \& \mathrm{p}=0.000\right)$ respectively.

Table (5.2) :Frequency Distribution of The study Participant Regarding to Total Knowledge Score of Inhaler $(n=142)$.

\begin{tabular}{|c|c|c|c|c|c|}
\hline \multirow{2}{*}{ Level of knowledge } & \multicolumn{2}{|c|}{ Physician $(n=40)$} & \multicolumn{2}{|c|}{ Nurse $(n=102)$} & \multirow{2}{*}{$\begin{array}{c}\text { Significant } \\
\text { (p value) }\end{array}$} \\
\hline & No & $\%$ & No & $\%$ & \\
\hline $\begin{array}{l}\text { Total level of knowledge } \\
\text { Good } \\
\text { Average } \\
\text { Poor }\end{array}$ & $\begin{array}{c}39 \\
1 \\
0\end{array}$ & $\begin{array}{l}97.5 \\
2.5 \\
0.0\end{array}$ & $\begin{array}{l}42 \\
57 \\
3\end{array}$ & $\begin{array}{l}41.2 \\
55.9 \\
2.9\end{array}$ & $\begin{array}{l}\mathrm{X}^{2}=37.202 \\
\mathrm{P}=0.000 * *\end{array}$ \\
\hline $\begin{array}{l}\text { Medication technique effect } \\
\text { Good } \\
\text { Average } \\
\text { Poor }\end{array}$ & $\begin{array}{c}39 \\
1 \\
0\end{array}$ & $\begin{array}{l}97.5 \\
2.5 \\
0.0\end{array}$ & $\begin{array}{l}37 \\
54 \\
11\end{array}$ & $\begin{array}{l}36.3 \\
52.9 \\
10.8\end{array}$ & $\begin{array}{l}\mathrm{X}^{2}=43.312 \\
\mathrm{P}=0.000 * *\end{array}$ \\
\hline $\begin{array}{l}\text { Side effect and inhaler } \\
\text { complications } \\
\text { Good } \\
\text { Average } \\
\text { Poor }\end{array}$ & $\begin{array}{c}39 \\
1 \\
0\end{array}$ & $\begin{array}{l}97.5 \\
2.5 \\
0.0\end{array}$ & $\begin{array}{l}31 \\
46 \\
25\end{array}$ & $\begin{array}{l}30.4 \\
45.1 \\
24.5\end{array}$ & $\begin{array}{c}X^{2}=8.083 \\
P=U . U^{*}\end{array}$ \\
\hline $\begin{array}{l}\text { Effect of medication on } \\
\text { general health } \\
\text { Good } \\
\text { Average } \\
\text { Poor }\end{array}$ & $\begin{array}{c}32 \\
8 \\
0\end{array}$ & $\begin{array}{c}80.0 \\
20.0 \\
0.0\end{array}$ & $\begin{array}{l}33 \\
67 \\
2\end{array}$ & $\begin{array}{c}32.4 \\
65.7 \\
2.0\end{array}$ & $\begin{array}{l}X^{2}=26.389 \\
P=0.000 * *\end{array}$ \\
\hline
\end{tabular}

- $\quad$ p-value $\leq 0.05$ (significant) 
- $\quad * *$ p-value $\leq \mathbf{0 . 0 0 1}$ (highly significant)

Poor knowledge : less than 50\%,Average knowledge : 50-65\% ,Good knowledge :more than $65 \%$

HEALTH CARE PROVIDERS`KNOWLEDGE AND SKILLS etc... 
Table (5.3): there was a statistically significant relation between nurses and physician and their total skills scores of

Table (5.3) : Frequency Distribution of The study Participant Regarding Their Skills

Scores of Metered Dose Inhaler (MDI) Assessment $(n=142)$

\begin{tabular}{|c|c|c|c|c|c|c|c|c|c|}
\hline \multirow[t]{3}{*}{ Items } & \multicolumn{4}{|c|}{ Physician $(n=40)$} & \multicolumn{4}{|c|}{ Nurses $(n=102$} & \multirow{3}{*}{$\begin{array}{c}\text { Sig } \\
\text { (p value) }\end{array}$} \\
\hline & \multicolumn{2}{|c|}{ Not correct } & \multicolumn{2}{|c|}{ Correct } & \multicolumn{2}{|c|}{ Not correct } & \multicolumn{2}{|c|}{ Correct } & \\
\hline & No & $\%$ & No & $\%$ & No & $\%$ & No & $\%$ & \\
\hline $\begin{array}{l}\text { Remove the cap from } \\
\text { the inhaler. }\end{array}$ & 0 & 0.0 & 40 & 100.0 & 5 & 4.9 & 97 & 95.1 & $\begin{aligned} X 2 & =2.032 \\
\mathrm{P} & =0.15\end{aligned}$ \\
\hline Shake the inhaler. & 6 & 15.0 & 34 & 85.0 & 45 & 44.1 & 57 & 55.9 & $\begin{array}{c}X 2= \\
10.584 \\
\mathrm{P}=0.001^{*}\end{array}$ \\
\hline Hold inhaler upright. & 6 & 15.0 & 34 & 85.0 & 26 & 25.5 & 76 & 74.5 & $\begin{aligned} X 2 & =1.811 \\
P & =0.18\end{aligned}$ \\
\hline $\begin{array}{l}\text { Exhale to residual } \\
\text { volume. }\end{array}$ & 3 & 7.5 & 37 & 92.5 & 49 & 48.0 & 53 & 52.0 & $\begin{array}{c}X 2= \\
20.345 \\
\mathrm{P}= \\
0.000 * *\end{array}$ \\
\hline $\begin{array}{l}\text { Put mouthpiece } \\
\text { between lips and teeth } \\
\text { to seal the mouthpiece. }\end{array}$ & 7 & 17.5 & 33 & 82.5 & 2 & 2.0 & 100 & 98.0 & $\begin{array}{c}X 2= \\
17.103 \\
P=0.001^{*}\end{array}$ \\
\hline $\begin{array}{l}\text { Inhale slowly and } \\
\text { simultaneously and } \\
\text { activate the canister. }\end{array}$ & 7 & 17.5 & 33 & 82.5 & 2 & 2.0 & 100 & 98.0 & $\begin{array}{c}X 2= \\
11.687 \\
\mathrm{P}=0.001^{*}\end{array}$ \\
\hline $\begin{array}{l}\begin{array}{l}\text { Continue slow and } \\
\text { deep inhalation. }\end{array} \\
\end{array}$ & 1 & 2.5 & 39 & 97.5 & 3 & 2.9 & 99 & 97.1 & $\begin{aligned} X 2 & =0.020 \\
\mathrm{P} & =0.89\end{aligned}$ \\
\hline $\begin{array}{l}\text { Take inhaler out of } \\
\text { mouth and hold breath } \\
\text { for } 10 \text { seconds. }\end{array}$ & 0 & 0.0 & 40 & 100.0 & 23 & 22.5 & 79 & 77.5 & $\begin{array}{c}X 2= \\
10.763 \\
\mathrm{P}=0.001^{*} \\
\end{array}$ \\
\hline $\begin{array}{l}\text { Wait for 30-60 seconds } \\
\text { before repeating the } \\
\text { process. }\end{array}$ & 16 & 40.0 & 24 & 60.0 & 70 & 68.6 & 32 & 31.4 & $\begin{array}{l}X 2=0.866 \\
P=0.002^{*}\end{array}$ \\
\hline Mouth wash. & 5 & 12.5 & 35 & 87.5 & 35 & 34.3 & 67 & 65.7 & $\begin{array}{c}X 2=6.575 \\
\mathrm{P}=0.01 *\end{array}$ \\
\hline Total score & & No & & $\%$ & & No & & $\%$ & \\
\hline Good & & 38 & & 5.0 & & 67 & & 5.7 & $\begin{array}{l}\chi^{2}=12.939 \\
\mathrm{P}=0.002^{*}\end{array}$ \\
\hline Average & & 2 & & 5.0 & & 28 & & 77.5 & \\
\hline Poor & & 0 & & 0.0 & & 7 & & 6.9 & \\
\hline
\end{tabular}

- * p-value $\leq 0.05$ (significant)

- $* *$ p-value $\leq \mathbf{0 . 0 0 1}$ (highly significant)

Table (5.4): there was a statistically significant relation between nurses and physician and their total skills scores of metered dose inhaler $\left(\chi^{2}=12.939 \&\right.$ $\mathrm{p}=0.002$ ). accuhaler inhaler technique assessment $\left(\chi^{2}\right.$ $=9.850 \& \mathrm{p}=0.01$ ). 
Table (5.4):Frequency Distribution of the Study Participant Regarding Their Skills Scores of Accuhaler Inhaler Technique Assessment $(n=142)$.

\begin{tabular}{|c|c|c|c|c|c|c|c|c|c|}
\hline \multirow[t]{3}{*}{ Items } & \multicolumn{4}{|c|}{ Physician $(n=40)$} & \multicolumn{4}{|c|}{ Nurses $(n=102)$} & \multirow{3}{*}{$\begin{array}{l}\text { Significant } \\
\text { (p value) }\end{array}$} \\
\hline & \multicolumn{2}{|c|}{$\begin{array}{l}\text { Not } \\
\text { correct }\end{array}$} & \multicolumn{2}{|c|}{ Correct } & \multicolumn{2}{|c|}{$\begin{array}{l}\text { Not } \\
\text { correct }\end{array}$} & \multicolumn{2}{|c|}{ correct } & \\
\hline & $\mathrm{No}$ & $\%$ & No & $\%$ & No & $\%$ & No & $\%$ & \\
\hline $\begin{array}{l}\text { Keep Diskus } \\
\text { horizontal. }\end{array}$ & 0 & 0.0 & 40 & 100.0 & 6 & 5.9 & 96 & 94.1 & $\begin{aligned} X 2 & =2.457 \\
P & =0.12\end{aligned}$ \\
\hline Prepare Diskus. & 0 & 0.0 & 40 & 100.0 & 0 & 0.0 & 40 & 100.0 & $\mathrm{NA}$ \\
\hline $\begin{array}{l}\text { Exhale to residual } \\
\text { volume. }\end{array}$ & 4 & 10.0 & 36 & 90.0 & 54 & 52.9 & 48 & 47.1 & $\begin{array}{l}X 2=21.927 \\
\mathrm{P}=0.000 * *\end{array}$ \\
\hline $\begin{array}{l}\text { Put mouth piece } \\
\text { between lips and } \\
\text { teeth to seal } \\
\text { mouthpiece. }\end{array}$ & 7 & 17.5 & 33 & 82.5 & 3 & 2.9 & 99 & 97.1 & $\begin{array}{l}X 2=9.303 \\
P=0.002 *\end{array}$ \\
\hline $\begin{array}{l}\text { Inhale forcefully } \\
\text { and deeply. }\end{array}$ & 3 & 7.5 & 37 & 92.5 & 4 & 3.9 & 98 & 96.1 & $\begin{aligned} X 2 & =0.785 \\
P & =0.38\end{aligned}$ \\
\hline $\begin{array}{lr}\text { Remove } & \text { the } \\
\text { device } & \text { from } \\
\text { mouth } & \text { before } \\
\text { exhale. } & \end{array}$ & 0 & 0.0 & 40 & 100.0 & 5 & 4.9 & 97 & 95.1 & $\begin{array}{c}X 2=2.032 \\
P=0.15\end{array}$ \\
\hline $\begin{array}{l}\text { Hold breath for } \\
10 \text { seconds. }\end{array}$ & 2 & 5.0 & 38 & 95.0 & 15 & 14.7 & 87 & 85.3 & $\begin{array}{c}X 2=2.568 \\
P=0.11\end{array}$ \\
\hline $\begin{array}{l}\text { Exhale and wait } \\
30-60 \text { seconds for } \\
2^{\text {nd }} \text { use. }\end{array}$ & 15 & 37.5 & 25 & 62.5 & 66 & 64.7 & 36 & 35.3 & $\begin{array}{l}X 2=8.679 \\
P=0.003 *\end{array}$ \\
\hline Mouth wash. & 4 & 10.0 & 36 & 90.0 & 39 & 38.2 & 63 & 61.8 & $\begin{array}{c}X 2=10.850 \\
P=0.001 *\end{array}$ \\
\hline Total score & No & & $\%$ & & No & & $\%$ & & \\
\hline Good & 38 & & 95.0 & & 72 & & 70.6 & & $\begin{array}{c}X 2=9.850 \\
P=0.01 *\end{array}$ \\
\hline Average & 2 & & 5.0 & & 28 & & 27.5 & & \\
\hline Poor & 0 & & 0.0 & & 2 & & 2.0 & & \\
\hline
\end{tabular}

-* p-value $\leq 0.05$ (significant)

$* *$ p-value $\leq \mathbf{0 . 0 0 1}$ (highly significant)

Table (5.5): there no statistical significant relation between nurses and physician and their skills scores of aerolizer / hand haler technique. 
wafaa Mahmoud Elboraey et., al.

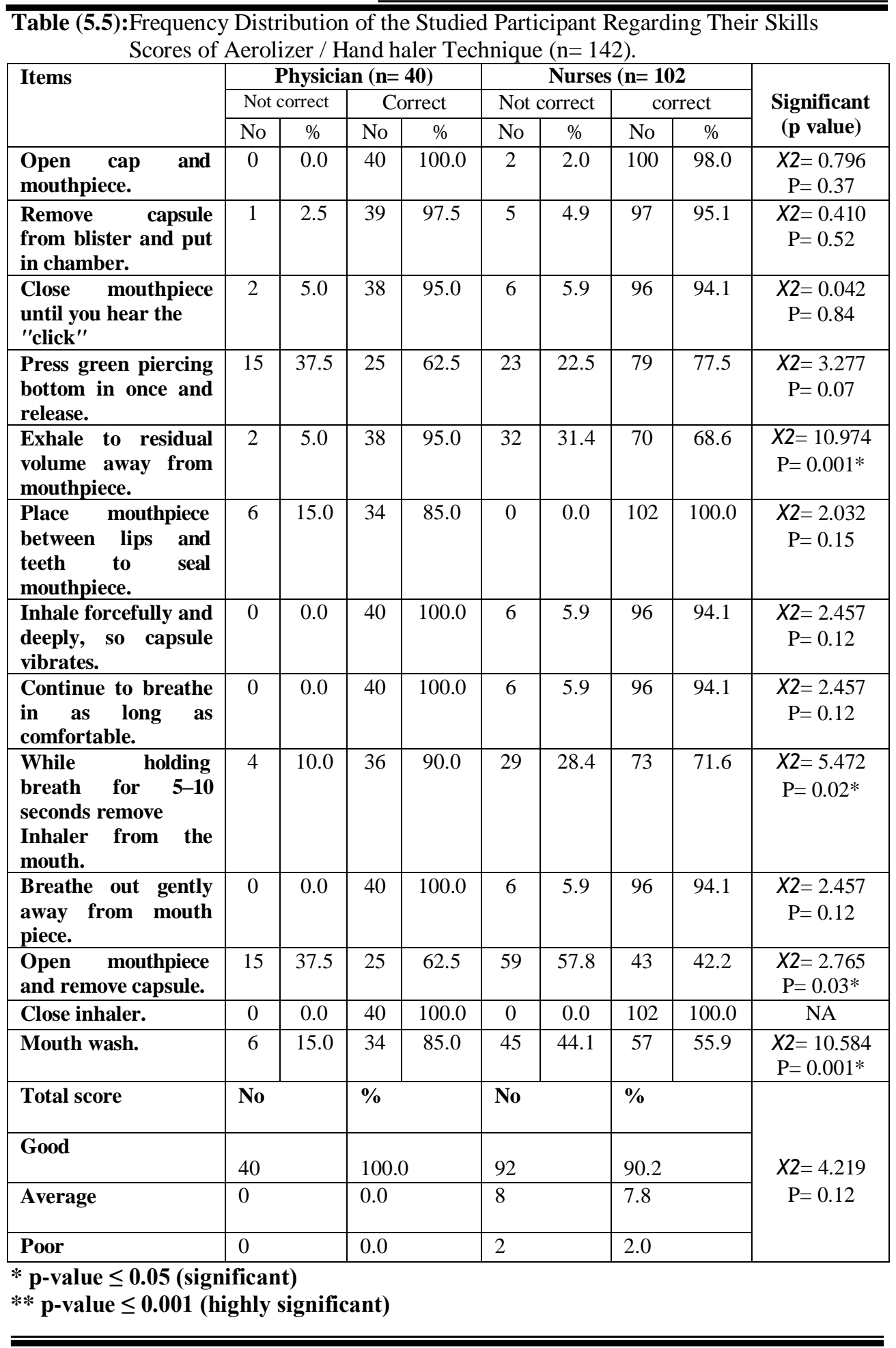


Table (5.6): shows that, there is a statistically significant relation between nurses and physician and their total score

Table (5.6): Frequency Distribution of the Study Participants according to their total score of Skills Related to Inhaler $(\mathrm{n}=142)$.

\begin{tabular}{|c|c|c|c|c|c|}
\hline \multirow[t]{2}{*}{ Total score } & \multicolumn{2}{|c|}{ Physician $(n=40)$} & \multicolumn{2}{|c|}{ Nurse $(n=102)$} & \multirow{2}{*}{$\begin{array}{r}\text { Significan } \\
(\mathrm{p} \text { value })\end{array}$} \\
\hline & No & $\%$ & No & $\%$ & \\
\hline Good & 40 & 100.0 & 81 & 79.4 & $X 2=9.665$ \\
\hline Average & 0 & 0.0 & 20 & 19.6 & $\mathrm{P}=0.01 *$ \\
\hline Poor & 0 & 0.0 & 1 & 1.0 & \\
\hline
\end{tabular}

$*$ p-value $\leq 0.05$ (significant)

$* *$ p-value $\leq 0.001$ (highly significant)

Discussion

Whilst the inhaled route is the first line administration method in the management of asthma, it is well documented that patients can have problems adopting the correct inhaler technique and thus receiving adequate medication. This applies equally to physician and nurses knowledge and skills related to inhaler use and leads to poor disease control and increased healthcare costs. So that the current study aimed to assess the health care providers' knowledge and skills related to inhaler medications techniques at Mansoura Chest Disease Hospital.

The current study focusing to find answers for five research questions the first research question is seeking to describe health care providers' knowledge related to inhaler medications, as known adequate knowledge will help to decrease inhaler use errors by the patients. The current study findings declared that there was a highly statistical significant difference between physician and nurses in relation to their level of knowledge, medication effect, inhalers side effect and inhaler complication and effect of medication on general health .This supported by Arora et al (2014) who reported that self-educated patients committed $100 \%$ error, while those trained by a doctor made $56.3 \%$ error. Nearly the of skills related to inhaler $\left(\chi^{2}=9.665 \&\right.$ $\mathrm{p}=0.01$ ). same results reported by Onyedum et al (2014).

In relation to the second question in the current study which seek to describe the health care providers' skills regarding inhaler. The current study portrays that, there was a statistically significant difference between physician and nurses regarding to their total skills level of metered dose inhaler. Where the physician shows better skills compared with nurses. The same findings was reported by Basheti, Qunaibi, Hamadi, Reddal (2014) as they studied health care providers (HCPs) in Jordan and found that all HCPs scored poorly in demonstrating the correct use of the dry powder inhalers when compared with pressurized metered-dose inhalers (MDIs) except specialist provider. They added that participants attending the workshop showed improved inhaler skills. Similarly, Alismail et al (2016) reported that the mean practical score of respiratory therapists was significantly higher compared with those of registered nurses and physicians.

Furthermore, the current study reflects that, there was a statistically significant difference between physician and nurses regarding to their total skills level of accuhaler inhaler technique. These findings supported by Giraud et al (2011) they found that inhaler training by pharmacists is feasible and seams to 
improve inhaler technique, asthma control and adherence.

This finding shed the light on the importance to focus on the inhaler technique which is associated with adherence and influences asthma control. Nurses and physician play an important role in teaching proper technique to the patients. Moreover, medication administration and patient's education ideally done by nurses so they have the major part of responsibility to do. Additionally, Specialists in asthma cannot devote all their time to patient education. Therefore, general physicians, together with nurses, public health nurses, and pharmacists can participate in education, while community-driven education is also desirable. Recently, expert pharmacists, who excel at educating inhalation techniques, have been generated in several regions.

The current study found that the majority of the physician and around three quarters of the studied nurses have good skills regarding MDI and Diskus devices. In contrast, De Tratto et al (2014) reported that overall misuse rates were high for both MDI and Diskus devices. There was poor correlation between perceived ability and investigator-measured performance of inhaler technique. Also they concluded that nurses are a key component of patient education in the hospital; however, nursing staff lack adequate knowledge of inhaler technique. So it is highly important to use face to face health education that enhances learning by doing or by demonstration in order to achieve better care.

The current study presents that, there was a statistically significant difference between physician and nurses regarding to their skills level of aerolizer / hand haler technique, the differences was in the following steps: exhale to residual volume away from mouthpiece, while holding breath for 5-10 seconds remove inhaler from the mouth, open mouthpiece and remove capsule, and mouth wash.

The current study portrays that, there were no statistical significant differences between physician and nurses regarding to their skills level of aerolizer / hand haler technique since neasrly all of them exhibit good skills regarding this technique. These findings confirmed by the study done in Japan (2017) that reflects that, a good relationship between physicians and patients is indispensable for appropriate treatment and they added that inhaler use skill teaching done by all staff member (Ichinose et al, 2017).

The results of the current study confirmed that, pharmacology education is a continuous task and is provided by specialized and trained team since highly qualified team either nurses or physician have a better skills. Nurses need pharmacology education so they can inform the patient of what they're giving why they're giving it and what it's going to do to them, and what to look out for (Nursing times team, 2011)

It is very important that when individuals are first prescribed inhaled medication it is essential to teach the patient about the correct use of their inhaler to ensure optimal drug delivery (Barber and Robbertson; 2015). This teaching must be done by nurses and physician continuous patient's education by demonstration is efficient and leads to better performance of both patients as well as health team.

In relation to the third research question which focused to declare the relationship between socio demographic characteristics and knowledge of health care providers; Where the majority of the nurses in the current study reported that they didn't receive any training courses regarding inhaler whereas, more than two fifths of physician received. Finally, there is a significant relation between the participant age, years of experience, and 
HEALTH CARE PROVIDERS`KNOWLEDGE AND SKILLS etc...

training courses and there is no statistical significant relation between physician's age and their total score of knowledge.

Additionally, there was no statistical significant relation between physician's level of education and their total score of knowledge these findings similar to $\mathrm{Al}$ Khalidi et al (2014) findings as they studied pharmacist knowledge and ability to inhalers they mentioned that a pharmacist's knowledge of inhaling devices is roughly proportional to the length of time the device has been available and that pharmacists form another group of health care professionals who require further teaching regarding inhaled medication delivery systems. It may be attributed to that health care providers not sufficiently aware of the importance of training and update their information regarding use of inhalers, Moreover, health care providers responsible for patient education which considered a critical factor in the use and misuse of medication inhalers that cannot be achieved without trained health care providers.

So it is highly important to provide on job training for all team member especially nurses. Accurate knowledge among nurses regarding inhaler use is a cornerstone in correcting patient wrong information and myths. Since poor knowledge among nurses will be reflected on patient information. This thought was reported by Nettikumara et al (2015) and Ranaut et al (2014) as they declared that a significant percentage of parents believed that 'inhalers may damage the lungs' and cause 'inhaler dependency'. These myths need corrections by proper nurse's knowledge.

The researcher in the current study stated a question related to the relation between the health care providers' socio demographic characteristics and their skills regarding inhaler use and the current study presents that, three quarters of nurses who have good and average total skills level aged 20-30 years and there was no statistical significant relation between nurse's age and their total score of practice. This finding was indicated that younger age nurses willing to perform better skills that may be attributed to that they still active and have a power for better skills. Better nurses' skills will be reflected on minimi ing client's erratum in medication use. Hence, a study done at New Delhi, India (2014) revealed that the majority of the studied patients made at least one error when using inhaler (Arora et al; 2014).

The current study presents that more than two thirds of those who have good level of total level of skills have Bachelor degree of nursing. That may be attributed to that highly educated nurses taught pharmacology course in their curriculum teaching agenda, as well as they are interested in such subjects. Finally, the surprising results shows that, nurses who exhibit good and average level of total practice didn't received training with no statistical relation. This finding may be attributed to that they have enough experiences or may be due to the actual lacking in training in their setting of practice.

Additionally, accurate knowledge provided by nurses to their patients affecting their medication compliance. In this regards, there was a progressive increase in asthma knowledge and an improvement in medication adherence among those who received an accurate health education according to Boulet et al (2015) findings. Furthermore, Zaraket et al (2011) concluded that, to improve asthma care in children, it is necessary to provide adequate education to parents. This education depends on better nurse's knowledge.

Moreover, Ali, Worku, Alemayehu and Gebrehiwot (2014) declared that they found very poor MDI technique was very common in healthcare providers. Despite 
involvement of all participants in patient counseling on inhalers, none of them were able to perform all steps correctly, which shows that patient may not have adequate instruction. These findings were presented in the current study where there was no a statistically significant relation between total level of knowledge and practice regarding Metered Dose Inhaler (MDI) assessment and accuhaler inhaler technique, and aerolizer / hand haler technique among nurses this results answer the fifth question in the current study that seeking to declare the relation between health care providers' knowledge and skills. These findings may be attributed to lack of training provided to them, and lack of awareness about the importance of such skill improvement. And highlight the importance of skill improvement in order to provide a high quality care; that considered the main role of the nursing staff.

Diverse inhaler devices causing a big challenge for health-care professionals and clarify why it is highly important to have clear and complete information about patient medication administration technique as well as a better performance and a better plan for good practice (Alismail et al., 2016). So nurses play a unique role in all practice concerning medication administration. So the current study aims are very delicious and tackling important issue in the field of nursing, and push toward better care.

Conclusion:The findings of this study concluded that:

There was a highly statistical significant relation between nurses and physician and their total level of knowledge, medication effect, side effect and inhaler complication and effect of medication on general health.There was a statistically significant relation between nurses and physician and their skills scores of metered dose inhaler (MDI) assessment items.
There was a statistically significant relation between nurses and physician and their total skills scores of accuhaler inhaler technique assessment.There was a statistically significant relation between nurses and physician and their skills scores of aerolizer / hand haler technique. With no statistical significant relation. Furthermore, there is a statistically significant relation between nurses and physician and their total score of skills related to inhaler.

Recommendations:In the light of the results of the present study, the following recommendations are suggested:

- Training courses for nurses and physician about new advances related to asthma and COPD medications.

- Evidence-based medication guidelines and protocols should be available at the chest hospitals.

Further researches are proposed to

- Evaluate the effect inhaler technique training among health-care professionals of on the asthma care quality outcomes.

- Pattern of medication use among patients suffering from asthma: a retrospective study.

- The quality of life of patient with asthma who using diverse inhaler devices.

- The effect of applying non pharmacological intervention on asthma care outcomes.

Acknowledgments: Specialthanks from the author to the participant in the current study, thanks also to hospital coordinators. Reference:

1. Muralidharan, P., Hayes Jr, D., \& Mansour, H. M. (2015). Dry powder inhalers in COPD, lung inflammation and pulmonary infections. Expert opinion on drug delivery, 12(6), $947-$ 962.

2. Virchow, J. C., Akdis, C. A., Darba, J., Dekhuijzen, R., Hartl, S., Kobelt, G., ... 
HEALTH CARE PROVIDERS`KNOWLEDGE AND SKILLS etc...

\& Plich, A. (2015). A review of the value of innovation in inhalers for COPD and asthma. Journal of market access \& health policy, 3(1), 28760

3. Celli, B. R., MacNee, W. A. T. S., Agusti, A. A. T. S., Anzueto, A., Berg, B., Buist, A. S., ... \& Fein, A. (2012). Standards for the diagnosis and treatment of patients with COPD: a summary of the ATS/ERS position paper. European Respiratory Journal, 23(6), 932-946.

4. Rogliani, P., Calzetta, L., Coppola, A., Cavalli, F., Ora, J., Puxeddu, E., ... \& Cazzola, M. (2017). Optimizing drug delivery in COPD: The role of inhaler devices. Respiratory Medicine.

5. Ranaut, V., Kaur, S., Kaur, S., \& Singh, M. (2014). Compliance and myths regarding use of Metered Dose Inhaler amongst caregivers of children suffering with asthma. Nursing and Midwifery Research, 10(1), 1.

6. Melani, A. S., Bonavia, M., Cilenti, V., Cinti, C., Lodi, M., Martucci, P., ... \& Neri, M. (2011). Inhaler mishandling remains common in real life and is associated with reduced disease control. Respiratory medicine, 105(6), 930-938.

7. Scichilone, N. (2015). Asthma control: the right inhaler for the right patient. Advances in therapy, 32(4), 285-292.

8. Desalu, O. O., Salawu, F. K., Jimoh, A. K., Adekoya, A. O., Busari, O. A., \& Olokoba, A. B. (2011). Diabetic foot care: self reported knowledge and practice among patients attending three tertiary hospital in Nigeria. Ghana medical journal, 45(2):60-65.

9. Rocha, R. M., Zanetti, M. L., \& Santos, M. A. D. (2009). Behavior and knowlege: basis for prevention of diabetic foot. Acta Paulista de Enfermagem, 22(1), 17-23

10. Al Khalidi D, Mahdy A, El kilany N, Al Chikhoni F, thabit F, Khan S. Pharmacist Knowledge \& Ability to
Use Inhaled Medication Delivery Systems in UAE. IOSR Journal Of Pharmacy (e)-ISSN: 2250-3013, (p)ISSN: 2319-4219 www.iosrphr.org Volume 4, Issue 7 (July 2014), PP. 45 4945 .

11. Nettikumara, N., Malaviarachchi, K., Dissanayaka, Y., Gunaratna, U, Wijesundara, S\& Wanasundara, W (2015). Myths and beliefs of long-term care providers towards starting inhaled medications in children with bronchial asthma. Sri Lanka Journal of Child Health, 4(4).

12. Ranaut V, Kaur S, Kaur S, Singh M. Compliance and myths regarding use of Metered Dose Inhaler amongst caregivers of children suffering with asthma. Nursing and Midwifery Research Journal, Vol-10, No.1, January 2014.

13. Zaraket, R., Al-Tannir, M. A., Abdulhak, B., Aref, A., Shatila, A., \& Lababidi, H. (2011). Parental perceptions and beliefs about childhood asthma: a cross-sectional study. Croatian medical journal, 52(5), 637-643.

14. Arora P, Kumar L, Vohra V, Sarin R, Jaiswal A, Puri M, Rathee D, Chakraborty P. Evaluating the technique of using inhalation device in COPD and Bronchial Asthma patients. Respiratory Medicine (2014) 108, 992e998.

15. Onyedum, C. C., Desalu, O. O., Nwosu, N. I., Chukwuka, C. J., Ukwaja, K. N., \& Ezeudo, C. (2014). Evaluation of inhaler techniques among asthma patients seen in Nigeria: An observational cross sectional study. Annals of medical and health sciences research, 4(1), 67-73.

16. Basheti, I, Qunaibi, E, Hamadi, S \& Reddel, H (2014). Inhaler technique training and health-care professionals: effective long-term solution for a 

current problem. Respiratory care, 59(11), 1716-1725.

17. Alismail A, Song C, Terry M, Daher N, Almutairi W, Lo T. Diverse Inhaler Devices: A Big Challenge for HealthCare Professionals. Respir Care 2016;61(5):593-599.

18. Ali H, Worku G, Alemayehu A, Gebrehiwot S. Competence in metered dose inhaler technique among dispensers in Mekelle. Allergy, Asthma \& Clinical Immunology 2014, 10:18.
19. Giraud V, Allaert F, Roche N. Inhaler technique and asthma: Feasibilityand acceptability of training by pharmacists. Respiratory Medicine (2011) 105, 1815e1822

20. De Tratto, K., Gomez, C., Ryan, C. J., Bracken, N., Steffen, A., \& Corbridge, S. J. (2014). Nurses' knowledge of inhaler technique in the inpatient hospital setting. Clinical Nurse Specialist, 28(3), 156-160.

21. Ichinose, M., Sugiura, H., Nagase, H., Yamaguchi, M., Inoue, H., Sagara, H., ... \& Ohta, K. (2017). Japanese guidelines for adult asthma 2017. Allergology International, 66(2), 163-189.

22. Barber P, Robertson D (2015). Essentials ofPharmacology for Nurses. $3^{\text {rd }}$ ed. Open University Press:USA. 